\title{
Human-wildlife coexistence: attitudes and behavioural intentions towards predators in the Maasai Mara, Kenya
}

Femke Broekhuis, Michael Kaelo

Dominic Kantai Sakat and Nicholas B. Elliot

\begin{abstract}
Living alongside predators can entail substantial costs both in terms of livelihoods and personal safety. Negative interactions with predators can lead to negative attitudes and behavioural intentions such as retaliatory or pre-emptive killing. As a result, conservation strategies are increasingly adopting human-wildlife coexistence approaches aimed at minimizing the costs associated with living with predators by providing direct or indirect benefits. This is done in the hope that people will foster positive attitudes and behavioural intentions towards predators. However, people's attitudes and their behavioural intentions are not necessarily linked, and both need to be understood for conservation actions to be effective. We conducted 747 semi-structured interviews with community members in the Maasai Mara, Kenya, to determine which factors influenced people's attitudes and behavioural intentions towards predators and whether the two were linked. Most interviewees $(57.52 \%)$ had a positive attitude towards predators as measured by their assertion that people, livestock and predators should coexist. Their attitude was dependent on benefits, occupation, conservancy membership and perceived community ownership of predators, but was not influenced by the costs of livestock depredation. Most respondents who were members of a conservancy had positive attitudes towards predators but this differed by conservancy, suggesting that, in addition to benefits, conservation politics could influence attitudes. In total, $10.3 \%$ of respondents said that they would kill a predator if it killed their livestock. This behavioural intention was only influenced by the respondent's attitude. Understanding the factors that influence attitudes and behavioural intentions will aid future management and coexistence strategies.
\end{abstract}

Keywords Attitude, behavioural intention, benefits, costs, human-wildlife coexistence, Maasai Mara, predator, tolerance

Femke Broekhuis† (Corresponding author), Michael KaElo* and Dominic Kantai SAKat* Mara Cheetah Project, Kenya Wildlife Trust, P.O. Box 86, 00502 Karen, Nairobi, Kenya. E-mail femke.broekhuis@gmail.com

Nicholas B. Elliot† Mara Lion Project, Kenya Wildlife Trust, Nairobi, Kenya

*Also at: Mara Lion Project, Kenya Wildlife Trust, Nairobi, Kenya

$\dagger$ Also at: Wildlife Conservation Research Unit, Department of Zoology, University of Oxford, The Recanati-Kaplan Centre, Tubney House, Tubney, UK

Received 14 August 2017. Revision requested 23 November 2017.

Accepted 12 January 2018. First published online 27 July 2018
Supplementary material for this article is available at https://doi.org/10.1017/So030605318000091

\section{Introduction}

T iving alongside predators can inflict substantial costs on Llocal communities through loss of livelihoods and risk of life (Thirgood et al., 2005; Inskip \& Zimmermann, 2009; Acha et al., 2018). These costs can often lead to negative attitudes (Kansky \& Knight, 2014) or negative behaviours towards predators (Inskip \& Zimmermann, 2009; Marchini \& Macdonald, 2012). Negative behaviours can include the retaliatory or pre-emptive killing of predators (e.g. Loveridge et al., 2017) and it is believed that this has resulted in the decline or local extirpation of many carnivore populations (Treves \& Karanth, 2003). Although attitudes can be a useful predictor of behavioural intentions (Kraus, 1995) this is not necessarily the case as the Theory of Planned Behaviour predicts that behavioural intentions can also be influenced by subjective norms and perceived behavioural control (Ajzen, 1991; Fishbein \& Ajzen, 2011). Hence it is possible that the underlying determinants of attitudes and behavioural intentions differ (Liu et al., 2011; Harvey et al., 2017). Therefore, understanding the factors that influence both attitudes and behavioural intentions towards wildlife, independent of each other, is essential in informing conservation interventions (Manfredo, 2009; Harvey et al., 2017).

As negative interactions with predators are often considered to be the root cause of negative attitudes and behaviours towards predators (Madden \& McQuinn, 2014), minimizing these negative interactions has become central to conservation efforts (Eklund et al., 2017). Minimizing these negative interactions can broadly be achieved through exclusion or coexistence strategies. Exclusion strategies rely on humans and wildlife being separated through, for example, the erection of physical barriers such as fences (e.g. Massey et al., 2014), the removal of wildlife from anthropogenic landscapes (e.g. Treves \& Karanth, 2003), the removal of people from wildlife areas (e.g. Karanth, 2007) or a combination of these. However, exclusion policies can lead to negative attitudes towards conservation (e.g. Ite, 1996) and could have significant ecological consequences. Fencing, for example, is a particularly contentious issue (Creel et al., 2013; Packer et al., 2013a, b) as it leads to habitat 
fragmentation and loss of connectivity between protected areas (Creel et al., 2013). This is particularly important in dryland and migratory ecosystems (Durant et al., 2015) such as the Maasai Mara in Kenya. Coexistence, on the other hand, is a 'dynamic but sustainable state in which humans and large carnivores co-adapt to living in shared landscapes where human interactions with carnivores are governed by effective institutions that ensure long-term carnivore population persistence, social legitimacy, and tolerable levels of risk' (Carter \& Linnell, 2016). Although it is difficult to influence the adaptation of carnivores, human adaptation can be promoted by minimizing the negative effects of predators and fostering positive attitudes through various, usually financial, incentives, a strategy that has proliferated in the Maasai Mara (Homewood et al., 2012; Courtney, 2015).

In Maasailand, efforts to reduce the costs of livestock predation by predators include compensation and insurance schemes (e.g. Maclennan et al., 2009; Bauer et al., 2017), fortification of livestock enclosures (e.g. Lichtenfeld et al., 2015) and the use of deterrents (e.g. Ogada et al., 2003). Benefits are largely associated with wildlife-based activities such as tourism. Wildlife, and especially big cats, attract tourists (Mossaz et al., 2015). High predator densities in the Maasai Mara (Broekhuis \& Gopalaswamy, 2016; Elliot \& Gopalaswamy, 2017) together with the spectacle of the annual wildebeest migration have resulted in the Maasai Mara National Reserve being the highest-earning wildlife area in Kenya (Narok County Council \& Trans-Mara County Council, 2012). However, some question whether tourism-related benefits really translate into coexistence with wildlife (Homewood et al., 2012).

Other than socio-economic costs and benefits, factors such as conservation politics could play a role in people's attitudes and behavioural intentions towards predators. Goldman et al. (2013), who describe conservation politics as the 'uneven power dynamics related to land-use and conservation decision making', report cases where Maasai killed lions Panthera leo as a political statement as they felt increasingly alienated by management and let down by government. There are many cases in Maasailand where the Maasai are resentful towards conservation efforts, especially when they are prohibited from cultural practices or excluded from key resources, such as grazing (Homewood et al., 2012; Goldman et al., 2013; Hazzah et al., 2013; Bedelian \& Ogutu, 2017). It has been shown that providing access to resources (Measham \& Lumbasi, 2013), including the local community in decision-making (Treves et al., 2009) and providing a sense of predator ownership (Dolrenry, 2013), can influence positive attitudes and behavioural intentions towards predators. As such, it is increasingly being recognized that a collaborative, rather than a top-down, approach whereby local communities are actively involved in conservationrelated decisions, is required for conservation initiatives to be successful (Redpath et al., 2017). Taking a collaborative approach can also overcome human-human conflict, the conflict between humans over the value of predators, which can hinder conservation efforts (Redpath et al., 2015).

In the Maasai Mara the relationship between coexistence strategies and people's attitudes and behaviours towards predators is unclear. Here we assess whether people's attitudes and behaviours towards predators are influenced by the costs, benefits or factors relating to conservation politics. We hypothesized that costs, as measured by livestock lost to predators, would have a negative effect on people's attitudes and behaviour towards predators, whereas the perceived presence of benefits would have a positive effect. As management regimes of the various wildlife areas differ in their level of inclusion of the community we hypothesized that this, and a person's sense of ownership of wildlife, would influence people's attitudes and behavioural intentions towards predators.

\section{Study area}

The Maasai Mara landscape in south-west Kenya is home to the Maasai people who, historically, were a semi-nomadic pastoralist community but are now largely sedentary (Seno \& Shaw, 2002). Traditionally, Maasai predominantly kept cattle but more recently there has been a shift to small stock, particularly sheep Ovis aries and goats Capra hircus, as these are more drought resistant (Bedelian \& Ogutu, 2017; Broekhuis et al., 2017).

Subdivision and privatization of communally owned land surrounding the Maasai Mara National Reserve occurred in 1999 and gave rise to concerns that livestock production would decrease (Seno \& Shaw, 2002) and cultivation and fencing would increase, leading to a decline in wildlife (Lamprey \& Reid, 2004). As a result, tourism companies partnered with local landowners to form wildlife conservancies where landowners receive a fixed, monthly payment for leasing their land for wildlife-based activities on the condition that the landowner moves off that land and does not cultivate or develop it (Thompson et al., 2009; Osano et al., 2013). At the time this study was conducted, there were nine conservancies of varying size and with their own private management (Fig. 1). Each conservancy comprises individually-owned parcels of land (46-850 landowners). Different lease agreements by the conservancies have resulted in varied management policies. Conservancy-specific management policies are not publicly available for all the conservancies (but see Osano et al., 2013; Bedelian, 2014; Bedelian \& Ogutu, 2017), but some of the differences are as follows: lease fees vary per conservancy (USD 30-50 per ha per year); some conservancies utilize a percentage of the tourism revenue to run various community development programmes (Bedelian, 2014; Courtney, 2015); some 


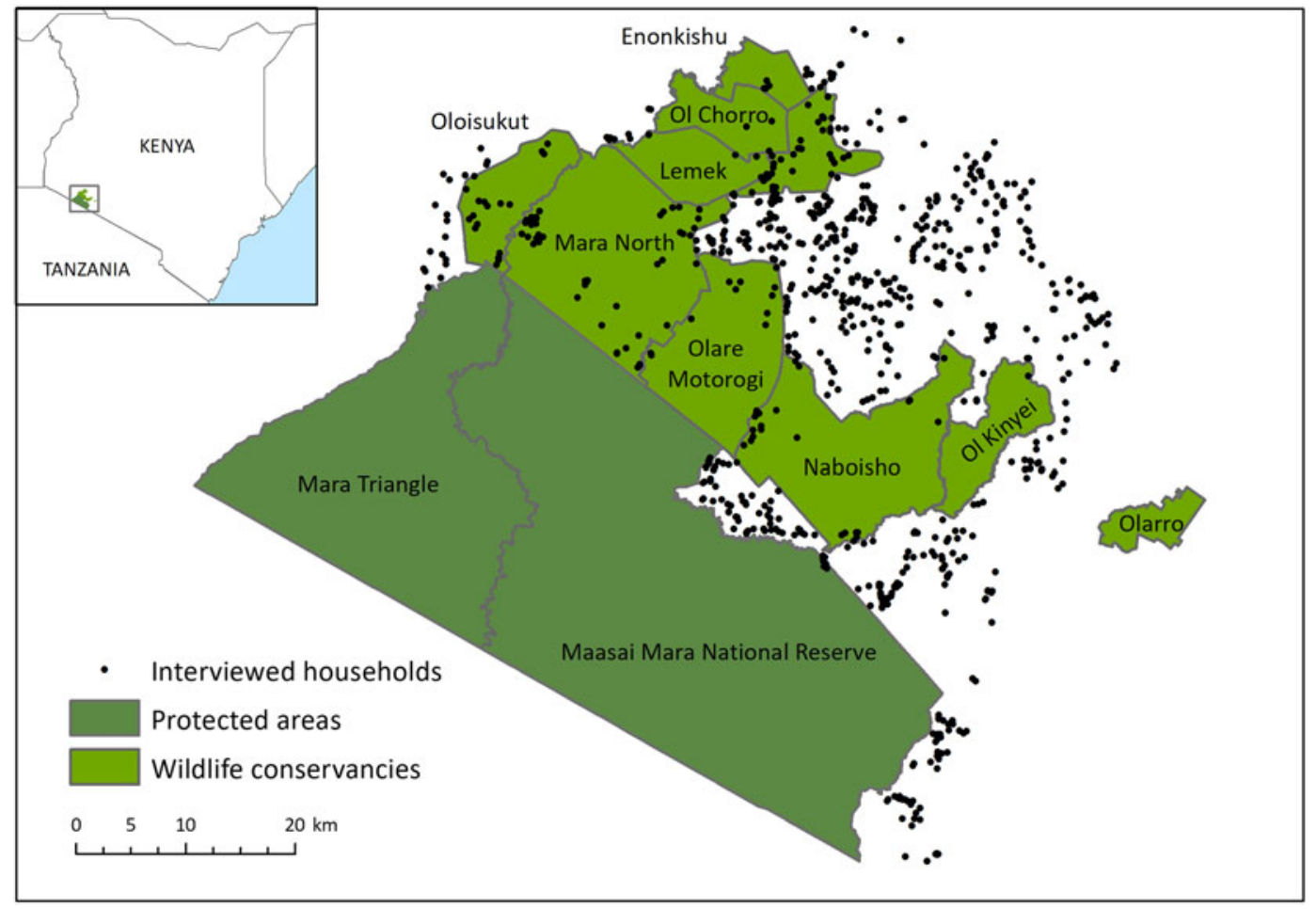

FIG. 1 The study area in south-west Kenya where 747 structured interviews were conducted to assess people's attitudes and behavioural intentions towards predators in and around the wildlife areas in the Maasai Mara.

conservancies have a board that comprises both tourism partners and landowners, where landowners are included in the decision-making process (Bedelian, 2014); some conservancies allow controlled grazing of cattle or enforce a livestock depredation insurance policy, whereas others do not. As with the Maasai Mara National Reserve, illegal grazing does occur within the conservancies, resulting in fines that can cause animosity, especially during dry periods when resources are scarce (Bedelian \& Ogutu, 2017). In the Maasai Mara National Reserve and the conservancies, the tourist lodges offer employment, frequently to local people, and pay additional lease fees to landowners (Thompson \& Homewood, 2002; Narok County Council \& Trans-Mara County Council, 2012; Bedelian, 2014).

There are no physical barriers between the wildlife areas and the surrounding community, and people, livestock and wildlife come into contact, which can result in negative interactions. In the Maasai Mara, Kolowski \& Holekamp (2006) found that the main predator species that caused conflict were spotted hyaenas Crocuta crocuta $(53 \%)$, leopards Panthera pardus (32\%) and lions (15\%; Kolowski \& Holekamp, 2006) but cheetahs Acinonyx jubatus also occasionally predate on small stock (Broekhuis et al., 2018a). Broekhuis et al. (2017) found that during a 3-month period most households lost an average of $3.5 \%$ of their livestock to depredation. This loss can have significant financial implications, especially as livestock is the main source of income
(Homewood et al., 2012). Furthermore, Maasai people invest a cultural value in livestock that exceeds their economic worth, making losses difficult to bear (Galaty, 1982).

\section{Methods}

\section{Data collection}

Data were collected using semi-structured interviews (Supplementary Material 1) conducted in June and July 2015. Ten Maasai men from the community, who had previous experience in conducting questionnaire-based interviews, were employed to conduct the survey. Before the survey the interviewers attended a full-day workshop in which they were tested on their interviewing and note-taking skills and their ability to use a GPS. The questionnaire was written in English but the interviews were conducted in Maasai. During the workshop each question was discussed and translated into Maasai to ensure consistency in translations between interviewers.

We were interested in the effect of livestock depredation on attitudes and behavioural intentions, so 820 households that kept livestock were randomly selected for the survey (see Broekhuis et al., 2017, for details). The most senior male of each household was interviewed, as they own the livestock and land, with the interviewer returning at a 
later date if he was not present. Interviews where data were missing were excluded from the analysis $(\mathrm{N}=17)$. To minimize incentives for exaggerating answers, prior to each interview the interviewee was informed that the survey was independent of the government or any management companies and that no compensation would be provided for livestock losses. Before the interview the purpose was fully explained by the interviewer and the respondents were therefore not misled in any way. Respondents were also informed that they could withdraw from the interview at any time without penalty and that they did not have to answer any questions if they did not want to. The interview commenced only once informed consent was given verbally. All data were treated with strict anonymity, by removing any personal identifiers, and confidentiality. All respondents agreed to be interviewed.

\section{Assessing attitudes and behavioural intentions}

As predators are not restricted to the wildlife areas and edge effects can have significant negative impacts on protected predator populations (Loveridge et al., 2010), our questionnaire was designed to examine the attitudes and behavioural intentions of people living within or on the periphery of wildlife areas (Fig. 1). Predators are present throughout this area (Madsen \& Broekhuis, in press) and we therefore decided to measure attitudes towards predators by asking the question 'should people and livestock live alongside predators?'. We defined a 'no' or 'yes' answer as being a negative or positive attitude respectively. Individuals that were 'unsure' $(\mathrm{N}=33)$ were excluded from further analyses. To determine behavioural intentions, respondents were asked 'What do you do when your livestock has been killed by a predator?' to which respondents could select one or more of the following answers: nothing, chase predator away, call authorities, call predator projects, kill predator, or other. For the analysis, the answers were condensed into those that answered they would kill a predator and those that did not select this answer. Killing predators is illegal in Kenya and doing so can incur a fine of KES 20 million (USD 222,000; exchange rate USD $1=$ KES 90 in 2015), life imprisonment or both (Kenyan Wildlife and Conservation Act, 2013 (No. 47 of 2013)). Therefore, this question was asked and interpreted as a hypothetical behavioural intention rather than a self-reported behaviour.

People's behaviour towards predators can be influenced by several factors, including the costs and benefits associated with predators, inclusion in conservation decisions and having a sense of ownership of predators. To quantify the costs of living with predators, respondents were asked how many livestock they had lost to predators in the 3 months prior to the interview. Respondents were also asked whether they thought there were any benefits associated with predators and, if so, what these benefits were. This was an open question and responses were grouped based on their similarities. When asked about their primary source of income respondents could choose from the following categories: tourism sector, agriculture, pastoralism, business or other. The respondents were then asked whether they leased land to a conservancy and, if so, which conservancy. Respondents who were members of Lemek, Ol Chorro Oiroua, Olarro, Oloisukut and Enonkishu conservancies $(\mathrm{N}=23)$ were excluded from analysis because of the small sample size, leaving 747 non-conservancy members and members of Naboisho, Ol Kinyei, Olare-Motorogi and Mara North. Lastly, respondents were asked whether they thought that the predators belonged to the community or the authorities.

\section{Analyses}

Attitudes and behavioural intentions towards predators were analysed separately using a Generalized Linear Model with a binomial error structure and logit link function. For attitudes the response was either yes (people should live alongside predators $=1$ ) or no (people should not live alongside predators $=0$ ). Similarly, for behavioural intentions, the response was either yes (would kill a predator $=1$ ) or no (would not kill a predator $=0$ ) in response to livestock depredation. The predictor variables used to determine attitudes and behavioural intentions were self-reported livestock loss, primary source of income, conservancy membership, and perceptions of whether there were benefits associated with predators and whether the predators belonged to the community. Additionally, we included respondents' attitudes in the behavioural intentions model. The candidate models were ranked using the Akaike Information Criterion (AIC) and when one model was superior this was used, otherwise parameter estimates were averaged across models with AIC differences $<2$ correcting for model weights (Burnham \& Anderson, 2002). Parameter estimates $(\beta)$ are presented with their 95\% confidence intervals (CI) and are considered to be statistically significant if the $95 \%$ CI does not overlap zero. All statistical analyses were performed in $R$ 3.3.o (R Development Core Team, 2016).

\section{Results}

In total, data from 747 interviews were used to determine people's attitudes and behavioural intentions towards predators in the Maasai Mara. Of these, 587 respondents $(75.78 \%)$ had lost at least one head of livestock to predators in the 3 months prior to the interview and 443 respondents (59.30\%) thought there were benefits associated with having predators. The benefits that the respondents named were largely related to tourism, employment, income and 
development, but some respondents also mentioned ecological benefits (i.e. predators kill herbivores) and aesthetics (Table 1). The majority of respondents derived their primary source of income from pastoralism $(n=553,74 \%)$ followed by tourism $(n=112,15 \%)$, business $(n=46,6 \%)$ and agriculture $(\mathrm{n}=22,3 \%)$. Of the 747 respondents, $392(52 \%)$ did not lease land to a conservancy and over half of the respondents $(n=429,57.43 \%)$ felt that the predators in the area belonged to them rather than to the government or the conservancies.

\section{Attitudes}

More than half of the respondents ( $n=432,57.52 \%)$ thought that people and livestock should live alongside predators. Their response to this question was not associated with the number of livestock that were lost $(\beta=0.008$, $\mathrm{CI}=-0.004-0.020)$ but the belief that predators were associated with benefits did have a positive influence ( $\beta=1.709$, $\mathrm{CI}=1.294-2.124)$. In other words, the majority of respondents who said that predators bring benefits also thought that people and their livestock should coexist with them (Fig. 2). Similarly, the majority of the respondents who said that predators belonged to the community thought that people, livestock and predators should coexist $(\beta=1.286$, $\mathrm{CI}=0.888-1.683$; Fig. 2). In addition, a higher proportion of respondents who were members of a conservancy responded 'yes' to the question about whether people and livestock should coexist with predators than did respondents who were not members of a conservancy, but this effect differed by conservancy $\left(\chi^{2}=135.08, d f=4, P<0.001\right.$; Fig. 2$)$. Of the four conservancies, the majority of the respondents who were members of Olare-Motorogi, Naboisho and Mara North thought that people and livestock should live alongside predators but this was not the case for members of $\mathrm{Ol}$ Kinyei. Respondents who were members of Ol Kinyei differed significantly from the three other conservancies $(\mathrm{P}<0.001)$ in that they thought that people and livestock should not live alongside predators, which was similar to respondents who were not members of a conservancy $(\mathrm{P}=1.000)$. Occupation also had an effect $\left(\chi^{2}=30.59, \mathrm{df}=4\right.$, $\mathrm{P}<$ 0.001; Fig. 2) and a higher proportion of respondents working in the tourism industry thought that people and livestock should live alongside predators compared to agriculturists $(\mathrm{P}=0.001)$, pastoralists $(\mathrm{P}=0.001)$, business people $(\mathrm{P}=0.001)$ and other groups $(\mathrm{P}=0.034)$.

\section{Behavioural intention}

Only a small number $(\mathrm{n}=79,10.30 \%)$ said they would kill a predator if it killed their livestock. The majority of respondents $(72.52 \%)$ said that they would call the authorities (Table 2). The behavioural intention of killing a predator if it killed a respondent's livestock was not influenced by
TABLE 1 Summary of the benefits that respondents $(n=747)$ associated with the presence of predators in the Maasai Mara, Kenya. Respondents could select one or more answers so for each answer the per cent represents how many of the 747 respondents gave this answer.

\begin{tabular}{ll}
\hline Benefit & $\begin{array}{l}\text { \% of } \\
\text { respondents }\end{array}$ \\
\hline None & 39.74 \\
Employment & 26.84 \\
Income & 32.39 \\
Tourism & 25.16 \\
Development & 7.61 \\
Indirect benefits (i.e. building of clinics) & 2.58 \\
Kill herbivores \& thereby reduce competition for & 1.68 \\
$\quad$ grass & \\
Kill wildebeest so reduce the presence of diseases & 0.39 \\
$\quad$ that kill livestock & \\
Aesthetic value & 0.65 \\
\hline
\end{tabular}

the number of livestock that were killed $(\beta=0.008$, $\mathrm{CI}=-0.006-0.021)$, the benefits associated with predators $(\beta=-0.309, \quad C I=-0.914-0.196)$, whether the respondent thought that predators belonged to the community $(\beta=0.143, C I=-0.390-0.677)$ or the respondent's occupation $\left(\chi^{2}=5.712, \mathrm{df}=4, \mathrm{P}<0.223\right)$. However, respondents' behavioural intentions were influenced by their attitude towards predators $(W=-0.571, \mathrm{CI}=-1.048--0.101)$ as the majority of respondents that did not think that people and livestock should coexist with predators said that they would kill a predator if it killed their livestock.

\section{Discussion}

The majority of respondents agreed that people and livestock should live alongside predators and this attitude influenced a respondent's behavioural intention towards predators if it killed their livestock. It is possible that, because it is illegal to kill predators, some respondents did not respond truthfully to the hypothetical question about whether they would kill a predator if it killed their livestock. Despite this, the results were significant and are likely to be conservative. In addition, the results are corroborated by other studies, especially those conducted in Maasailand (e.g. Romañach et al., 2007; Marchini \& Macdonald, 2012; Hazzah et al., 2014; Hazzah et al., 2017).

Respondents' attitudes towards predators were influenced by multiple variables but not by the cost of losing livestock. This is similar to findings in other areas (Zimmermann et al., 2005) but it is possible that attitudes could be influenced by loss relative to overall wealth rather than by absolute losses (Romañach et al., 2007; Inskip \& Zimmermann, 2009). In addition, costs were measured over a 3-month time-frame and it is possible that attitudes 
Benefits

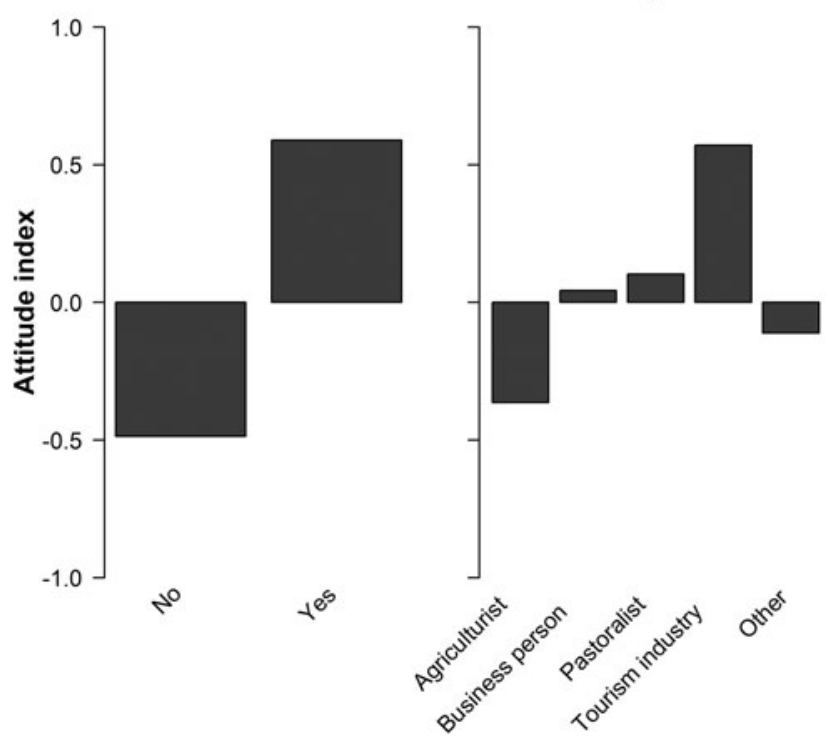

Membership

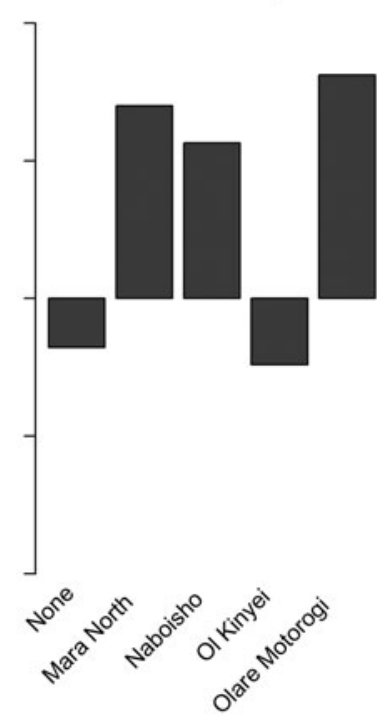

Ownership

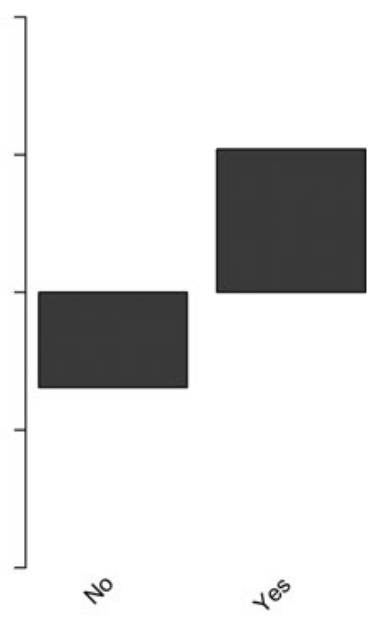

FIG. 2 Index of attitude towards predators in the Maasai Mara, Kenya (Fig. 1), in relation to benefits, occupation, conservancy membership and community ownership of predators. Values $>$ o indicate more positive than negative responses and vice versa. The index was calculated for each category within a variable using the formula: Attitude Index $=(p-q) /(p+q)$ to give a standardized ratio of the number of respondents (of 747) that said 'yes' in a group $(p)$ to the number of people that said 'no' in a group ( $q$ ), with values ranging from -1 to 1 .

TABLE 2 Summary of the behavioural intentions towards predators in the Maasai Mara if a respondent's livestock were killed by a predator. Respondents could select one or more answers so for each answer the per cent represents how many of the 747 respondents gave this answer.

\begin{tabular}{ll}
\hline Behavioural intention & \% of respondents \\
\hline Call authorities & 72.52 \\
Chase predator & 54.16 \\
Call predator projects & 20.34 \\
Kill predator & 10.30 \\
Nothing & 13.87
\end{tabular}

*This includes the Mara Cheetah Project, the Mara Lion Project and the Mara Hyena Project.

are shaped by historic or prolonged costs (Kansky \& Knight, 2014). Alternatively, experiencing damage might not always be a driver of attitudes (Kansky et al., 2014) as intangible costs, such as fear or alienation, rather than tangible costs, such as direct monetary losses, might be a better predictor of attitudes (Kansky \& Knight, 2014).

Our results showed that benefits and employment in the tourism industry had a positive influence on respondents' attitudes towards predators. However, in terms of employment, only a small percentage of the people interviewed (15\%) obtained their main income from being employed in the tourism industry. This is supported by previous findings in the Maasai Mara that income from tourism-based activities only contribute to a small proportion of households (Homewood et al., 2012) and favour a small elite (Lamprey \& Reid, 2004). Therefore, employment in the tourism industry is likely to influence only the attitudes of a small proportion of the population. However, the majority of the benefits mentioned by the respondents were related to tourism either directly through development, sale of craftwork or visits to cultural bomas, or indirectly through leasing land to conservancies for wildlife-based activities. Because of these socio-economic benefits, tourism has increased rapidly in the Maasai Mara (Lamprey \& Reid, 2004). Although using tourism to link conservation and better livelihoods is a popular tool, it is not always successful (Kiss, 2004). Therefore, care needs to be taken in putting too much emphasis on tourism, as high volumes of tourism can have negative ecological impacts (Broekhuis, 2018b; Buckley et al., 2016) that can consequently destroy the tourism product and can be negatively affected by both national and international events (Homewood et al., 2012). As the tangible benefits (i.e. employment) were mentioned more often than the intangible benefits (i.e. aesthetic value) we suggest that alternative, wildlife-based incomes, such as conservation payments, should be considered. For example, in Belize, people who are part of a jaguar Panthera onca camera-trap programme receive payments for captures of jaguars and other key wildlife (Harvey et al., 2017).

A higher proportion of respondents who were members of a conservancy believed that people and livestock should 
live alongside predators compared to those who did not lease land to a conservancy. This is probably because of the multitude of benefits offered to conservancy members (Bedelian, 2014; Courtney, 2015). However, this was not consistent across the conservancies examined. Conservancies can provide important resources for livestock in terms of grass, water and salt licks, especially during the dry season, but prohibiting access to these resources can create animosity (Bedelian \& Ogutu, 2017). For example, Hazzah et al. (2013) found that restricted access to resources during the dry season was linked to both negative attitudes and behavioural intentions towards lions. As access to resources differ per conservancy, this could reflect the differences in attitudes towards predators between the different conservancy members. In addition, animosity could be increased when herders are fined for grazing in areas or during times when access is prohibited (Bedelian \& Ogutu, 2017). Similarly, the presence of compensation (through an insurance scheme that members pay into) and the inclusion of landowners in the decision-making process varied across the wildlife areas. This inclusion could be an important factor to consider, especially as a higher number of respondents who felt that the predators belonged to the community, rather than the authorities, thought that people, livestock and predators should coexist. Inclusion, through a sense of ownership and community engagement, is an important part of effective conservation strategies (Madden \& McQuinn, 2014) and our results suggest that conservation politics are likely to influence people's attitudes. We propose that once management plans are made public, the factors influencing these differences are explored, as this would aid future management and coexistence strategies.

We focused our survey on men as Maasai men own the land and livestock and are often associated with the killing of predators, especially lions (e.g. Goldman et al., 2013). However, recent research has shown that women value benefits, such as conservancy membership, differently to men (Keane et al., 2016) and that women may be less tolerant towards predators than men (e.g. Carter \& Allendorf, 2016; Harvey et al., 2017). We would therefore advise that women are included in future surveys relating to attitudes and behavioural intentions towards predators. In addition, we measured attitude and behavioural intentions as a dichotomous response but it is likely that both attitudes and behavioural intentions lie on a continuous scale (Treves, 2012). By assessing attitudes and behavioural response on a continuous scale, the strength of these could be measured (Harvey et al., 2017; Hazzah et al., 2017).

It is encouraging that more than half of the respondents thought that people, livestock and predators should coexist, especially as exclusion strategies, such as fencing of Africa's wildlife areas (Packer et al., 2013a), are increasingly advocated. However, fencing of an ecosystem such as the Maasai Mara, where free movement is critical for the access of transient resources would be detrimental to both wildlife and people (Notenbaert et al., 2012). As predator populations are negatively impacted by edge effects (Loveridge et al., 2010), the overall willingness of respondents to coexist with predators bodes well for their conservation. However, a relatively large proportion of respondents (42.48\%) felt that people, livestock and predators should not coexist. In the long term, this could have an impact on predator populations as people may wish to exclude predators from community land that has not been set aside for wildlife-based activities. Our results suggest that focusing on the benefits, rather than the costs, associated with predators, could be a more effective strategy to foster attitudes favouring coexistence. In addition, promoting a sense of ownership of predators may enhance a willingness to coexist. We acknowledge that more work is needed to understand better the complexities of coexistence within this landscape. We propose that future research is conducted within a Theory of Planned Behaviour framework by including factors such as subjective norms and perceived behavioural control (Ajzen, 1991) and we hope that our findings will provide a starting point.

Acknowledgements We thank the National Council for Science and Technology, Narok County Government, the Maasai Mara Wildlife Conservancies Association and the community for permission to carry out this study, Basecamp Foundation Kenya for providing funding to allow us to conduct the interviews, and the African Wildlife Foundation for funding the barazas (local meetings) in which the results were presented and discussed with the community. Additional funding was provided by WWF and through donations to the Kenya Wildlife Trust. We thank Francis Sopia for feedback on the questionnaire and for fruitful discussions, Clevers Ntokoiwuan, Njapit Pariken, Miton Taki, Pesi Saning'o, Daniel Momposhi, Charles Nkoitoi, Noosaron Simoren, Wilson Rotiken, Danson Kaelo and David Naurori for conducting the interviews, the respondents for volunteering their time, Fiona Tande for assisting with data entry, and the reviewers for their valuable critiques.

Author contributions Conceived and designed the study: FB, MK, DKS and NBE. Trained the interviewers: MK and DKS. Supervised data collection: FB, MK and DKS. Informal analysis: MK and DKS. Formal analysis: FB and NBE. Data validation: FB and MK. Wrote the paper: FB and NBE. Revised and edited the paper: MK and DKS.

\section{Conflicts of interest None.}

Ethical standards Permissions to conduct the questionnaire survey were granted by the National Council for Science and Technology (Permit No.: NACOSTI/P/15/9772/5795), Narok County Government, the Maasai Mara Wildlife Conservancies Association and the community. 


\section{References}

Acha, A., Temesgen, M. \& Bauer, H. (2018) Human-wildlife conflicts and their associated livelihood impacts in and around Chebera-Churchura National Park, Ethiopia. Society \& Natural Resources, 31, 260-275.

Ajzen, I. (1991) The theory of planned behavior. Organizational Behavior and Human Decision Processes, 50, 179-211.

Bauer, H., Muller, L., Van Der Goes, D. \& Sillero-Zubiri, C. (2017) Financial compensation for damage to livestock by lions Panthera leo on community rangelands in Kenya. Oryx, 51, 106-114.

Bedelian, C. (2014) Conservation, tourism and pastoral livelihoods: wildlife conservancies in the Maasai Mara, Kenya. $\mathrm{PhD}$ thesis. University College London, London, UK.

Bedelian, C. \& Ogutu, J.O. (2017) Trade-offs for climate-resilient pastoral livelihoods in wildlife conservancies in the Mara ecosystem Kenya. Pastoralism, 7, 1-22.

Broekhuis, F. (2018b) Natural and anthropogenic drivers of cub recruitment in a large carnivore. Ecology and Evolution, http://doi. org/10.1002/ece3.4180.

Broekhuis, F., Cushman, S.A. \& Elliot, N.B. (2017) Identification of human-carnivore conflict hotspots to prioritise mitigation efforts. Ecology and Evolution, 7, 10630-10639.

Broekhuis, F. \& Gopalaswamy, A.M. (2016) Counting cats: spatially explicit population estimates of cheetah (Acinonyx jubatus) using unstructured sampling data. PLoS ONE, 11, e0153875.

Broeknuis, F., Thuo, D.N. \& Hayward, M.W. (2018a) Feeding ecology of cheetahs in the Maasai Mara, Kenya and the potential for intra- and interspecific competition. Journal of Zoology, 304, 65-72.

Buckley, R.C., Morrison, C. \& Castley, J.G. (2016) Net effects of ecotourism on threatened species survival. PLoS ONE, 11, e0147988.

Burnham, K.P. \& Anderson, D.R. (2002) Model Selection and Multimodel Inference: A Practical Information-Theoretic Approach. Springer-Verlag, New York, USA.

Carter, N.H. \& Allendorf, T.D. (2016) Gendered perceptions of tigers in Chitwan National Park, Nepal. Biological Conservation, 202, 69-77.

Carter, N.H. \& Linnell, J.D.C. (2016) Co-adaptation is key to coexisting with large carnivores. Trends in Ecology \& Evolution, 31, $575-578$.

Courtney, C.H.A. (2015) Sustainable Africapitalism? Grassroots perceptions of Maasai Mara Conservancies and their relationship with development. $\mathrm{PhD}$ thesis. University of Edinburgh, Edinburgh, UK.

Creel, S., Becker, M.S., Durant, S.M., M'Soka, J., Matandiko, W., Dickman, A.J. et al. (2013) Conserving large populations of lions-the argument for fences has holes. Ecology Letters, 16, 14131413.

Dolrenry, S. (2013) African lion (Panthera leo) behavior, monitoring, and survival in human-dominated landscapes. $\mathrm{PhD}$ thesis. The University of Wisconsin-Madison, Madison, USA.

Durant, S.M., Becker, M.S., Creel, S., Bashir, S., Dickman, A.J., Beudels Jamar, R.C. et al. (2015) Developing fencing policies for dryland ecosystems. Journal of Applied Ecology, 52, 544-551.

Eklund, A., López-Bao, J.V., Tourani, M., Chapron, G. \& Frank, J. (2017) Limited evidence on the effectiveness of interventions to reduce livestock predation by large carnivores. Scientific Reports, 7, 2097.

Elliot, N.B. \& Gopalaswamy, A.M. (2017) Toward accurate and precise estimates of lion density. Conservation Biology, 31, 934-943.

Fishbein, M. \& Ajzen, I. (2011) Predicting and Changing Behavior: The Reasoned Action Approach. Taylor \& Francis, New York, USA Galaty, J.G. (1982) Being "Maasai"; being "people-of-cattle": ethnic shifters in East Africa. American Ethnologist, 9, 1-20.
Goldman, M.J., De Pinho, J.R. \& Perry, J. (2013) Beyond ritual and economics: Maasai lion hunting and conservation politics. Oryx, 47, 490-500.

Harvey, R.G., Briggs-Gonzalez, V. \& Mazzotti, F.J. (2017) Conservation payments in a social context: determinants of tolerance and behavioural intentions towards wild cats in northern Belize. Oryx, 51, 730-741.

Hazzah, L., Bath, A., Dolrenry, S., Dickman, A. \& Frank, L. (2017) From attitudes to actions: predictors of lion killing by Maasai warriors. PLOS ONE, 12, e0170796.

Hazzah, L., Dolrenry, S., Kaplan, D. \& Frank, L. (2013) The influence of park access during drought on attitudes toward wildlife and lion killing behaviour in Maasailand, Kenya. Environmental Conservation, 40, 266-276.

Hazzah, L., Dolrenry, S., Naughton, L., Edwards, C.T.T., Mwebi, O., Kearney, F. et al. (2014) Efficacy of two lion conservation programs in Maasailand, Kenya. Conservation Biology, $28,851-860$

Homewood, K.M., Trench, P.C. \& Brockington, D. (2012) Pastoralist livelihoods and wildlife revenues in East Africa: a case for coexistence? Pastoralism: Research, Policy and Practice, 2, 1-23.

Inskip, C. \& Zimmermann, A. (2009) Human-felid conflict: a review of patterns and priorities worldwide. Oryx, 43, 18-34.

Ite, D.U.E. (1996) Community perceptions of the Cross River National Park, Nigeria. Environmental Conservation, 23, 351-357.

Kansky, R., Kidd, M. \& Knight, A.T. (2014) Meta-analysis of attitudes toward damage-causing mammalian wildlife. Conservation Biology, 28, 924-938.

KAnsky, R. \& KNight, A.T. (2014) Key factors driving attitudes towards large mammals in conflict with humans. Biological Conservation, 179, 93-105.

Karanth, K.K. (2007) Making resettlement work: the case of India's Bhadra Wildlife Sanctuary. Biological Conservation, 139, 315-324.

Keane, A., Gurd, H., Kaelo, D., Said, M.Y., de Leeuw, J., RowClifFe, J.M. et al. (2016) Gender differentiated preferences for a community-based conservation initiative. PLOS ONE, 11, e0152432.

KIss, A. (2004) Is community-based ecotourism a good use of biodiversity conservation funds? Trends in Ecology \& Evolution, 19, 232-237.

Kolowski, J.M. \& Holekamp, K.E. (2006) Spatial, temporal, and physical characteristics of livestock depredations by large carnivores along a Kenyan reserve border. Biological Conservation, 128, 529-541.

Kraus, S.J. (1995) Attitudes and the prediction of behavior: a metaanalysis of the empirical literature. Personality and Social Psychology Bulletin, 21, 58-75.

Lamprey, R.H. \& Reid, R.S. (2004) Expansion of human settlement in Kenya's Maasai Mara: what future for pastoralism and wildlife? Journal of Biogeography, 31, 997-1032.

Lichtenfeld, L.L., Trout, C. \& Kisimir, E.L. (2015) Evidence-based conservation: predator-proof bomas protect livestock and lions. Biodiversity and Conservation, 24, 483-491.

Liu, F., McShea, W.J., Garshelis, D.L., Zhu, X., Wang, D. \& Shao, L. et al. (2011) Human-wildlife conflicts influence attitudes but not necessarily behaviors: factors driving the poaching of bears in China. Biological Conservation, 144, 538-547.

Loveridge, A.J., Hemson, G., Davidson, Z. \& Macdonald, D.W. (2010) African lions on the edge: reserve boundaries as 'attractive sinks'. In Biology and Conservation of Wild Felids (eds D.W. Macdonalds \& A.J. Loveridge), pp. 283-304. Oxford University Press, Oxford, UK.

Loveridge, A.J., Valeix, M., Elliot, N.B. \& Macdonald, D.W. (2017) The landscape of anthropogenic mortality: how African lions respond to spatial variation in risk. Journal of Applied Ecology, 54, $815-825$. 
Maclennan, S.D., Groom, R.J., Macdonald, D.W. \& Frank, L.G. (2009) Evaluation of a compensation scheme to bring about pastoralist tolerance of lions. Biological Conservation, 142, 24192427.

Madden, F. \& McQuinn, B. (2014) Conservation's blind spot: the case for conflict transformation in wildlife conservation. Biological Conservation, 178, 97-106.

Madsen, E.K. \& Broekhuis, F. (in press) Determining multi-species site use outside the protected areas of the Maasai Mara, Kenya, using false positive site-occupancy modeling. Oryx.

Manfredo, M.J. (2009) Wildlife and Society: The Science of Human Dimensions. Island Press, Washington, DC, USA.

Marchini, S. \& Macdonald, D.W. (2012) Predicting ranchers' intention to kill jaguars: case studies in Amazonia and Pantanal. Biological Conservation, 147, 213-221.

Massey, A.L., King, A.A. \& Foufopoulos, J. (2014) Fencing protected areas: a long-term assessment of the effects of reserve establishment and fencing on African mammalian diversity. Biological Conservation, 176, 162-171.

Measham, T.G. \& Lumbasi, J.A. (2013) Success factors for community-based natural resource management (CBNRM): lessons from Kenya and Australia. Environmental Management, 52, 649-659.

Mossaz, A., Buckley, R.C. \& Castley, J.G. (2015) Ecotourism contributions to conservation of African big cats. Journal for Nature Conservation, 28, 112-118.

Narok County Council \& Trans-Mara County Council (2012) Maasai Mara National Reserve Management Plan 2012-2021. Http://geonode-rris.biopama.org/documents/863/download [accessed July 2017].

Notenbaert, A.M., Davies, J., De Leeuw, J., Said, M., Herrero, M., Manzano, P. et al. (2012) Policies in support of pastoralism and biodiversity in the heterogeneous drylands of East Africa. Pastoralism: Research, Policy and Practice, 2, 1-17.

Ogada, M.O., Woodroffe, R., Oguge, N.O. \& Frank, L.G. (2003) Limiting depredation by african carnivores: the role of livestock husbandry. Conservation Biology, 17, 1521-1530.

Osano, P.M., Said, M.Y., de Leeuw, J., Ndiwa, N., Kaelo, D., Schomers, S. et al. (2013) Why keep lions instead of livestock? Assessing wildlife-tourism based payment for ecosystem services involving herders in the Maasai Mara, Kenya. Natural Resources Forum, 37, 242-256.

Packer, C., Loveridge, A., Canney, S., Caro, T., Garnett, S.T., Pfeifer, M. et al. (2013a) Conserving large carnivores: dollars and fence. Ecology Letters, 16, 635-641.
Packer, C., Swanson, A., Canney, S., Loveridge, A., Garnett, S., Pfeifer, M. et al. (2013b) The case for fencing remains intact. Ecology Letters, 16, 1414-e1414.

R Development Core Team (2016) R: A Language and Environment for Statistical Computing. R Foundation for Statistical Computing, Vienna, Austria. Https://www.r-project.org [accessed June 2017].

Redpath, S.M., Bhatia, S. \& Young, J. (2015) Tilting at wildlife: reconsidering human-wildlife conflict. Oryx, 49, 222-225.

Redpath, S.M., Linnell, J.D.C., Festa-Bianchet, M., Boitani, L., Bunnefeld, N., Dickman, A. et al. (2017) Don't forget to look down-collaborative approaches to predator conservation. Biological Reviews, 92, 2157-2163.

Romañach, S.S., Lindsey, P.A. \& Woodroffe, R. (2007) Determinants of attitudes towards predators in central Kenya and suggestions for increasing tolerance in livestock dominated landscapes. Oryx, 41, 185-195.

SENO, S.K. \& SHAW, W. (2002) Land tenure policies, Maasai traditions, and wildlife conservation in Kenya. Society \& Natural Resources, 15, 79-88.

Thirgood, S., Woodroffe, R. \& Rabinowitz, A. (2005) The impact of human-wildlife conflict on human lives and livelihoods. In People and Wildlife, Conflict Or Co-existence? (eds R. Woodroffe, S. Thirgood \& A. Rabinowitz), pp. 13-26. Cambridge University Press, Cambridge, UK.

Thompson, D.M. \& Homewood, K. (2002) Entrepreneurs, elites, and exclusion in Maasailand: trends in wildlife conservation and pastoralist development. Human Ecology, 30, 107-138.

Thompson, D.M., Serneels, S., Kaelo, D.O. \& TrenCh, P.C. (2009) Maasai Mara-land privatization and wildlife decline: can conservation pay its way? In Staying Maasai? Livelihoods, Conservation and Development in East African Rangelands (eds K. Homewood, P. Kristjanson \& P.C. Trench), pp. 77-114. Springer, New York, NY.

Treves, A. (2012) Tolerant attitudes reflect an intent to steward: a reply to Bruskotter and Fulton. Society \& Natural Resources, 25, 103-104.

Treves, A. \& Karanth, K.U. (2003) Human-carnivore conflict and perspectives on carnivore management worldwide. Conservation Biology, 17, 1491-1499.

Treves, A., Wallace, R. \& White, S. (2009) Participatory planning of interventions to mitigate human-wildlife conflicts. Conservation Biology, 23, 1577-1587.

Zimmermann, A., Walpole, M.J. \& Leader-Williams, N. (2005) Cattle ranchers' attitudes to conflicts with jaguar Panthera onca in the Pantanal of Brazil. Oryx, 39, 406-412. 